\title{
REVIEWS ON THE USAGE OF SPECIFIC BORROWED UNITS IN THE LEXICON OF THE UZBEK LANGUAGE
}

\section{Khadicha Bobojonova}

Independent Researcher, Department of Uzbek Linguistics,

Urgench State University, Urgench, Uzbekistan.

\section{ABSTRACT}

This article highlights the acquiring principles of lexical, morphological and syntactic borrowings and their specific linguistic aspects in the Uzbek language. In the clarification of these issues, we relied on the experience of scholars who have conducted research on the lexicon of the Uzbek language.

\section{Keywords:}

inner source, outer source, lexical borrowings, morphological borrowings, syntactical borrowings.

Article Received: 18 October 2020, Revised: 3 November 2020, Accepted: 24 December 2020

\section{Introduction}

Humankind has always entered into interrelationship with each other throughout his consistent evolutionary development. The current period of high development has been reached on the basis of various forms of socio-economic, religious and scientific relations. Most of the linguistic scientific sources indicate the idea that any change in social life is first and foremost reflected in the language of that society. This philosophical axiom may be reasonably applied to the Uzbek language also.

"In the current globalization period, it is natural that every nation, every independent state pays prior attention to the provision of its national interests, in this regard, first and foremost, the preservational and developmental issues of its own culture, ancient values and mother tongue." Such ideas emphasize the need for extensive research on Uzbek linguistics and the study of its lexical structure by layers.

The nations dwelling on the area of Uzbekistan have experienced many turbulent periods from ancient times to the current day. Whereas our language came across with the ancient Indian (Sanskrit) and ancient Iranian languages in the ancient history (III-II centuries BC and VII-VIII centuries AD), while in certain periods of history (VIII-XII centuries), it was influenced by Arabic languages. will come. Our language, which came into contact with the Mongol-Chinese languages in the 13th century, developed under the strong influence of RussianEuropean languages from the second half of the 19th century to the end of the 20th century. This, in turn, provides the basic facts for explaining the processes of formation of the current image of the Uzbek language.

Several Uzbek linguists have expressed their ideas on the issue of borrowings in different linguistic layers of the Uzbek language in their works. One of the most significant work of them is "Lexical layers of the modern Uzbek literary language" by E. Begmatov. Moreover, most of our scholars who have studied the lexicon of the modern Uzbek language have learned certain ideas about borrowings in the language. In particular, in scientific publications such as "Lexicology of the Uzbek language" (1981), published under the edition of A.Khojiev and A.Akhmedov, "Modern Uzbek literary language" by H.Jamalkhanov (2005), "Modern literary Uzbek language" by Sh.Rakhmatullayev (2006), and "Lexicon of the Old Turkic Literary Language" (2015) by B. Abdushukurov, some scientific observations have been made on this issue. 
Furthermore, most of the dissertations defended in the field of lexicon in recent years have to some extent drawn conclusions and generalizations on the borrowed units to a certain extent. Nevertheless, in most of the abovementioned studies, borrowings are examined at the lexical level, mainly lexical borrowings are discussed.

Every language, which is a means of human communication, develops on the basis of two different materials. These are internal sources and external sources. If we look at the development of a particular language, it does so primarily through its own internal resources lexical richness and grammatical tools. In addition to internal sources, external sources also play an important role in the enrichment and improvement of the Uzbek language vocabulary. External sources usually refer to the enrichment of vocabulary through the borrowing of words from other languages. Due to the connection of the Uzbek language with other non-related languages, a certain number of words have been borrowed from other languages into Uzbek.

There is no language in the world that has not passed words into other languages or borrowed words from other languages. The Uzbek language does not bypass these laws. Numerous published sources confirm our abovementioned opinion.

Taking into the consideration that our motherland has also risen to high levels of development in certain periods of history, and that it has spread to the whole world as a hotbed of science, these views are not very unbased.

As N.A. Baskakov wrote, a number of lexical units from Turkic languages were transferred to Russian and through it to Western European languages in the XVI - XVII centuries. However, by the XX century, the inverse of the above phenomenon began to take effect, it is known from researches that through Russian, European-specific units were transferred to Turkic languages, in particular, the Uzbek language began to borrow linguistic units. There are also scientific sources about the adoption of Turkish linguistic units in Persian and Arabic, which proves once again that this process is not onesided.

Researches have shown that the presence of certain linguistic units in a language does not indicate that it is a unit of a language. For example, a number of factors need to be taken into account when determining from which language a linguistic unit, which is equally used in Uzbek, Persian, Arabic, or Russian-European languages, has been borrowed. This is not a simple phenomenon. It is true that in most scientific publications published so far, our language has always been in the background.

Nevertheless, in many studies today, a new approach, a new trend, has begun to emerge, that is, the tendency to prioritize the Uzbek language. This means that when we encounter a word or other linguistic element in another language, we believe that it is not as if that unit of language is really borrwed from that language, but rather from the point of view that it is borrowed from our language into that language.

As a result of economic, cultural, and political relations between peoples, the units inherent in the construction of a language (mainly lexical units, partly phonetic and grammatical units) are transferred to another language, absorbed into this language and become its wealth. In our opinion, it is expedient to develop a typology of units of borrowings in the Uzbek language, to study their functional-semantic development on the basis of modern scientific achievements, dividing them into groups in the form of lexical borrowings, morphological and syntactic borrowings.

Surprisingly, the research so far on the borrowings' layer has mostly covered only lexical units. In addition, the acquisition of such units was assessed only in terms of one-sidedness, that is, the borrowings of the Uzbek language. However, the second trend in modern Uzbek linguistics, that is, the transfer of many words from Uzbek (Turkish) to other languages in the world, is proving to be a real linguistic phenomenon. 
With this in mind, in this small study, in addition to the research on the layers of language in Uzbek linguistics, we also aim to reflect on not only borrowed words (lexical units), but also the affixal, syntactic, and phraseological acquisitions that are in use in the Uzbek language..

Researches claim that not only lexical units, but also morphological (affixal) units have been borrowed into Uzbek from other languages. It is possible to say that most of the affixes in the Uzbek language are elements related to the Persian language. The main part of them are noun affixes, such as -shunos, -kor (gar), -soz, vachcha, -furush, -xon, -xo'r, -boz (-voz), -bon, -paz, -dosh, -do'z, -navis, -kash. Moreover, the affixes -zor, -iston, -goh, which make up place names, are also among such units.

In addition, most of the affixes that make up the adjectives are considered to have been borrowed from Persian and Arabic. Although the most active affixes are in the form of prefixes, such as be-, ba-, no-, ser-, bad-, bar-, this type also include suffixes -dor, -simon, -mand//-vand, -parast, -parvar, -baxsh and affix morphemes derived from Arabic in the form -iy//-viy.

Affixal borrowings from Persian and Arabic can also be found among the adverb affixes. Such suffixes are related to Persian languages, such as -ona (oqilona (wisely), makkorona (cunningly), do'stona (friendly)), vor//-var (mardonavor (courageously); two borrowed affixes are used at the same time), namo (uyalgannamo (embarrassingly), oliftanamo (boastfully)), -omuz (hayratomuz (surprisingly)); and belonging to Arabic languages such as -an (qisman(partially), ruhan (spiritually), majburan (compulsorily)).

In the current period, the works on word formation in Uzbek claim that if the units, in particular, the affixes, used in another language, are borrowed together with the words in that language, these affixes are not considered belonging to Uzbek. Although some of the above affixes are used in the content of borrowings of those languages (this is mainly the case with affixes in Arabic), the vast majority of them are used with the units of pure Uzbek language. At the same time, it is not in line with our modern linguistic principles to consider words with suffixes that are used only in the lexemes of other languages as "root words". Therefore, we believe that such affixes can be considered as affixed morphemes.

In many studies conducted since the second half of the last century, majority of affixal assimilations, borrowed from the Russian language have been referred as a morphological borrowings in the Uzbek language. However, in the post-independence period, with the development of the Uzbek language, many of these affixes have almost become obsolete or inactive.

However, we can see that in certain styles of Uzbek language used today, such affixes have not lost their activity. For example, affixes such as (fizik (physical), akademik (academic), toponimik (toponymic), faktik

(factual), etnografik(ethnographic)), -ant (magistrant (master), formant (formant), -ist ( metodist (methodist)), -iv (obyektiv (objective), subyektiv (subjective)) are among the most active affixes in the scientific style today.

It is true that such affixes are mainly used in words of other languages, which can lead to controversy over whether we call them affixes of the Uzbek language. However, such units are used in certain texts in the Uzbek language, and according to international linguistic principles, we cannot call them anything other than affixes.

Numerous sources confirm that attempts to avoid such affixes in certain periods of the Uzbek language and to use morphological devices suitable for Uzbek orthoepy in their place have existed before. However, in some styles of the Uzbek language it was not possible to completely get rid of such affixes. In particular, in many branches of the scientific style, there was a need for the affixes mentioned in the description of various scientific issues.

There is another group of morphological units borrowed from the Persian languages, which we refer to as affixoids, based on the scientific 
literature, as they can also be evaluated as lexical units when appropriate.

To the category of morphological assimilations of this type of Persian languages, first of the units such as, -noma (taklifnoma (invitation card), bildirishnoma (notice), aybnoma (indictment)); -xona (bosmaxona (printing house), ishxona (workplace), yotoqxona (bedroom)) and they are placed after the root in the affixoid function. In our view, linguistic elements related to Persian languages, such as kam-, nim-, xush-, xom-, ham- which were considered to be components of a compound word in the 1970s, can also be considered as affixoids today.

For instance, "kam-", which is the first part of such adjectives as, kamchiqim (economical), kamsuqum (humble), kamquvvat(weak), kamgap(non-talkative), furthermore, "nim-" element that forms the reduction degree of the adjectives (nimqorong'i (slightly-dark), nimjon (weak), nimpushti (pinkish), nimchorak (quarter)) are functionallymorphologically almost indistinguishable from affixoids - xona and -noma.

In our opinion, prefixes such as xush- and ham-, which belong to Persian languages, can be considered as affixoids, depending on the context of some words. For example: xushovoz (euphonious), xushchaqchaq(cheerful), xushbichim(slim); hamtovoq (accomplices), hamfikr(consensus), hamjihat (united), hamsoya(neighbour), hamsuhbat (interlocutor) and etc.

There are several reasons for this conclusion: first, most of the borrowed units, such as kam-, nim-, xush-, xom-, ham- are very inactive in the Uzbek language. Second, the units in question are used in functions close to affixes. This provides ample grounds for classifying them as affixoids.

Summarizing the above, it should be noted that any language in the world will inevitably interact with other languages. There are no languages that do not accept linguistic means from other languages. There are specific principles for the borrowings of elements of other languages, the process of borrowing does not take place in a chaotic manner, but is based on certain linguistic laws.

Borrowed linguistic units can consist not only of words (lexemes), but also affixes, phraseological units, figurative expressions (paraphrases) of various forms, units of euphemistic compliments in communication.

We would like to draw your attention to another aspect. Several factors need to be considered when evaluating the phenomenon of borrowing a particular unit from one language to another. First of all, it should be kept in mind that a particular unit may have been borrowed from the first language to the second language, or from the second language to the first language. The second is that the unit itself may have been borrowed from other languages. This is especially common in European languages. In such cases, it is necessary to determine exactly from which language a particular borrowed linguistic unit was adopted and through which languages that unit passed before it reached our language.

\section{Conclusion}

In conclusion, the study of various aspects of modern Uzbek language units is important for a clearer picture of the different stages of development of our language, to ensure its purity and attractiveness in the further development of our language.

\section{References}

[1] Decree of the President of the Republic of Uzbekistan "On measures to radically increase the prestige and status of the Uzbek language as the state language" // People's Speech, October 22, 2019, № 218 (7448).

[2] Begmatov E. Lexical layers of modern Uzbek literary language. -Tashkent: Fan, 1965.

[3] Vafoiy A., Avezmetov Sh. Dictionary of Persian words in Uzbek language. -TehronTashkent: Movarounnahr, 2005; Ansoriddin Ibrahim. Dictionary of Urdu-Uzbek mutual words. - Tashkent: Teacher, 1998 
[4] Jumaniyozov O. Assimilation of RomanceGermanic languages in Uzbek. -Tashkent: Fan, 1987

[5] Yuldoshev T. Uzbek dialects in Tajikistan. Tashkent: Fan, 1986. Olloyorov Q. TurkishMongolian lexical parallels in Khorezm dialects. - Urgench: Philological research (collection), 2004.

[6] Baskakov N.A. Turkisms in the East Slavic languages. -M .: Nauka, 1974. -p 304

[7] Jumaniyozov O. Borrowings of RomanGerman languages in Uzbek. -Tashkent: Fan, 1987.

[8] Zakhidi A. Words of Turkic origin in modern Arabic. Author's abstract. dis. ... Candidate of Philological Sciences. -Baku, 1967. -P.7.

[9] Rahmatullayev Sh. Modern literary Uzbek language. -Tashkent: Universitet, 2003. p. 105

[10] Hojiev A. Uzbek word formation system. Tashkent: Teacher, 2007. -P.62-80.

[11] Uzbek grammar. G.Abdurahmanov et al. Tashkent: Fan, 1975. -P.277.

[12] Hojiev A. Uzbek word formation system. Tashkent: Teacher, 2007. -P.62-80; Rahmatullayev Sh. Modern literary Uzbek language. -Tashkent: Universitet, 2003. p.116

[13] Uzbek grammar. G.Abdurahmanov et al. Tashkent: Fan, 1975. -P.248

[14] Uzbek grammar. G.Abdurahmanov et al. Tashkent: Fan, 1975. -P.248

[15] 15. Rahmatullayev Sh. Modern literary Uzbek language. -Tashkent: Universitet, 2003. - p.116 